\title{
ERRATUM - revista Letras de Hoje edição v. 53, n. 3 (2018) - ID 30988
}

$\diamond$

A Equipe Editorial da revista Letras de Hoje torna pública as seguintes alterações na edição v. 53, n. 3, jul.-set. 2018, DOI: http://dx.doi.org/10.15448/1984-7726.2018.3, artigo "Eu e meus alunos-cotistas na escola pública": racismo, ethos discursivo, discurso midiático e produção de subjetividade, DOI: http://dx.doi.org/10.15448/1984-7726.2018.3.30988:

\section{Página 393 (Título)}

Onde se lê: "Eu e meus alunos-cotistas na escola pública": racismo, ethos discursivo, discurso midiático e produção de subjetividade

Leia-se: "Eu e meus alunos-cotistas na escola pública": racismo, ethos discursivo, discurso midiático e produção de subjetividade ${ }^{1}$

- Acrescentar nota de rodapé:

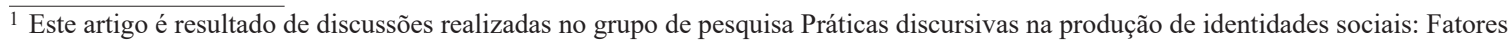
humanos, organizações, trabalho, tecnologia e sociedade (PRADISIS), que têm como um de seus focos principais questões de racismo em ambientes escolares, do qual fazem parte os três autores.

\section{Página 393 (Título em inglês)}

Onde se lê: "Me and my student-quota holders in public school": [...]

Leia-se: "Me and my quota student in public school": [...]

\section{Página 393 (Resumo)}

Onde se lê: Com foco na materialidade do discurso e seus efeitos de produção de subjetividade e em uma dada qualidade de real(idade) (ROCHA, 2006), buscamos problematizar sentidos que se constroem na tensão entre discursos racistas e antirracistas na contemporaneidade na construção de um ethos (MAINGUENEAU, 1997, 2006, 2006, 2008) de professora que aponta para uma figura salvadora.

Leia-se: Com foco na materialidade do discurso e seus efeitos de produção de subjetividade e em uma dada qualidade de real(idade) (ROCHA, 2006), buscamos problematizar sentidos que se constroem, na contemporaneidade, a partir da tensão entre discursos racistas e antirracistas, na construção de um ethos (MAINGUENEAU, 1997, 2006, 2006, 2008) de professora que aponta para uma figura que surge para salvar os alunos cotistas - que são necessariamente negros segundo o senso comum - numa evidente visão de mundo racista, que opõe professora e alunos aos "cotistas".

\section{Página 393 (Abstract)}

Onde se lê: The aim of this paper is to propose a discursive analysis of text produced by Cefet/RJ teacher, that triggered controversy in social networks. The testimony of the teacher, who turned on social networks, on experience with high school dropouts, was initially welcomed as an emotional and emotional report, the result of an "empathic and generous" attitude. Later, however, when it was "republished", it came to be read as the result of structuring racism that organizes social relations in the country and its author as a racist person. With a focus on the materiality of discourse and its effects of subjectivity production and on a given quality of real(ity) (ROCHA, 2006), we seek to problematize senses that are built on the tension between racist and antiracist discourses in contemporaneity in the construction of an ethos (MAINGUENEAU, 1997, 2006, 2006, 2008) of teacher that points to a savior figure. 
Leia-se: The aim of this paper is to propose a discursive analysis of a text produced by a teacher who works at Cefet/RJ, that triggered controversy in social networks. The testimony of the teacher, which went viral on social networks, was about her experience with high school quota students. It was initially welcomed as an emotional and touching report and as the result of an "empathic and generous" attitude. Later, however, when it was "republished", it came to be read as the result of the structuring racism that organizes social relations in Brazil. Besides that, its author came to be regarded as a racist person. By focusing on the materiality of discourse and its effects of subjectivity production and on a given quality of real(ity) (ROCHA, 2006), we seek to problematize meanings that are built on the tension between racist and antiracist discourses in contemporaneity in the construction of an ethos (MAINGUENEAU, 1997, 2006, 2006, 2008) of a teacher who points to a figure that emerges to save the quota students - who are necessarily black according to common sense - in an evident racist world view that opposes teacher and students to "quota students".

\section{Página 393 (Keywords)}

Onde se lê: student-quota holders

Leia-se: quota students

\section{Página 394, 1aㅡ coluna, 1ํo parágrafo}

Onde se lê: Publicado no Facebook, o depoimento, compartilhado por cerca de 15 mil pessoas e curtido por mais de $31 \mathrm{mil}^{1}$

Leia-se: $\quad$ Publicado no Facebook ${ }^{2}$, o depoimento, que chegou a ser compartilhado por cerca de 15 mil pessoas e curtido por mais de $31 \mathrm{mil}^{3}$

จ Acrescentar nota de rodapé 2 :

${ }^{2} \mathrm{O}$ texto originalmente foi publicado no blog da autora e posteriormente compartilhado no Facebook. Após a repercussão negativa, em 2017, o texto foi retirado das redes sociais da autora.

จ Acrescentar nota de rodapé 3 :

3 Informações disponíveis em: http://blogdovalente.com.br/noticias/educacao/2016/05/professora-faz-relato-emocionante-sobre-alunoscotistas-e-post-viraliza/.

\section{Página 394, 1a coluna, 20 parágrafo}

Onde se lê: As mídias tradicionais e as redes sociais se dividiram, uns defendendo a professora, outros atacando-a.

Leia-se: As mídias tradicionais e as redes sociais se dividiram, uns defendendo, outros atacando a professora.

Onde se lê: após se explicar em outro texto ${ }^{2}$

Leia-se: após se explicar em outro texto ${ }^{4}$

จ Alterar o número da nota de rodapé 2 para nota de rodapé 4

\section{Página 394, 1a coluna, 3o parágrafo}

Onde se lê: Nesse contexto, o objetivo deste artigo é propor uma análise discursiva do texto que deu origem à polêmica ora descrita, de modo a problematizar sentidos que se constroem na tensão entre discursos racistas e antirracistas na contemporaneidade.

Leia-se: Considerando, portanto os contextos de produção e circulação do texto e as questões étnico-raciais, temos como problema orientador da pesquisa a seguinte questão: de que modo se constrói o ethos discursivo do enunciador na referida publicação? Para responder a tal questão, propomos como objetivo geral, neste artigo, uma análise discursiva do texto que deu origem à polêmica ora descrita, de modo a problematizar sentidos que se constroem na tensão entre discursos racistas e antirracistas na contemporaneidade.

\section{Página 394, 2a coluna, 20 parágrafo}

Onde se lê: Na seguinte, apresentamos as análises; por último, nossas considerações finais.

Leia-se: $\quad$ Na seguinte, discutimos as análises discursivas do texto e, por último, apresentamos nossas considerações finais. 


\section{Página 394, 2aㅡ coluna, 6o parágrafo}

Onde se lê: [...] parte desses grupos. No caso do Cefet/RJ, por exemplo, [...]

Leia-se: [...] parte significativa desses grupos. Tal associação constrói-se com base numa lógica racista, na qual a relação entre grupos etnicamente marcados, principalmente por seu fenótipo, em nossa sociedade, se organiza em torno de discursos e práticas hierarquizantes e produtoras de desigualdades, seja com relação à classe social, à origem geográfica, às atividades profissionais dentre outras diferenças. Partindo dessa compreensão, Guimarães (2009, p. 36) explica que há casos em que,

(...) o preconceito e a discriminação pressupõem ou se referem à ideia de 'raça' de maneira central. Nestes, as demais diferenças são imagens figuradas de 'raça'. São casos em que a hierarquia social não poderia manter um padrão discriminatório sem as diferenças raciais.

No caso do Cefet/RJ, por exemplo, [...]

\section{Página 395, 1aㅡ coluna, 1 o parágrafo}

Onde se lê: [...] e com renda per capita inferior a 1,5 salário mínimo.

Leia-se: [...] e com renda per capita inferior a 1,5 salário mínimo. Portanto, no contexto do estado do Rio de Janeiro, os critérios que incluem classe social somam-se ao quesito raça na construção do perfil desse aluno dito cotista, alvo dessas políticas afirmativas.

\section{Página 395, 1aㅡ coluna, 2o parágrafo}

Onde se lê: problematizados e desconstruídos movimentos sociais e em trabalhos acadêmicos

Leia-se: problematizados e desconstruídos por movimentos sociais e trabalhos acadêmicos

\section{Página 395, 1aㅡ coluna, 3o parágrafo}

Onde se lê: produzida ela mesma pelos próprios sujeitos negros.

Leia-se: produzida ela mesma pelos próprios sujeitos negros. É o "racismo à brasileira", que, como explica o antropólogo Roberto da Matta (1997) tem sua manifestação de modo implícito, disfarçado e de difícil discussão, constituindo de modo geral um tabu entre os brasileiros.

Onde se lê: Nesse sentido, a produção de um discurso anti-cotas, seja ele assumido ou não como racista,

Leia-se: Nesse sentido, a produção de um discurso anticotas, assumido ou não como racista, ๑ com entrada de novo parágrafo

\section{Página 395, 2a coluna, 10 parágrafo}

Onde se lê: se legitimaram e naturalizaram em nossa cultura.

Leia-se: E é a naturalização de tais discursos que os tornam difíceis de serem desconstruídos, pois não se assumem como discursos segregadores. No entanto, acreditamos que a análise do discurso pode contribuir para essa desnaturalização, uma vez que seja possível identificar marcas linguístico-discursivas que possibilitem expor práticas racistas, machistas, homofóbicas, dentre outras práticas que ferem os direitos humanos.

$\vartheta$ com entrada de novo parágrafo

\section{Página 396, 2a coluna, 5o parágrafo}

Onde se lê: "Além da persuasão por argumentos, a noção de ethos permite de fato refletir sobre o processo mais geral da adesão de sujeitos a uma certa posição discursiva"

Leia-se: Além da persuasão por argumentos, a noção de ethos permite de fato, refletir sobre o processo mais geral da adesão de sujeitos a certa posição discursiva" 


\section{Página 397, 1aㅡ coluna, $3^{0}$ parágrafo}

Onde se lê: A escolha do gênero discursivo depoimento em redes sociais

Leia-se: A escolha do gênero discursivo depoimento em redes sociais ${ }^{5}$

จ Acrescentar nota de rodapé 5 :

$5_{5}$ Os excertos usados na análise e disponibilizados neste artigo foram obtidos pelo recurso de salvar (printar) as telas do smartphone, realizado por uma das autoras do artigo em 02 de maio de 2016, às 18:11h.

\section{Página 397, 1a coluna, 50 parágrafo}

Onde se lê: [...] leitura e reações por outros leitores para além do coenunciador construído.

Leia-se: [...] leitura e reações por outros leitores para além do coenunciador construído. Após a repercussão negativa em 2017, o texto foi retirado das redes sociais da autora, estando atualmente disponível apenas em blogs e sites de notícias.

\section{Página 397, 2- coluna, 20 parágrafo}

Onde se lê: Recorrer a enunciados implícitos no texto em questão, mostrou-se muito proveitoso visto que a autora, Leia-se: Recorrer a enunciados implícitos no texto em questão mostrou-se muito proveitoso visto que a autora,

\section{Página 397, 2a coluna, 2o parágrafo}

Onde se lê: relacionam-se a um interdiscurso de responsabilidade do interlocutor.

Leia-se: relacionam-se a um interdiscurso de responsabilidade do interlocutor. Vejamos a análise do excerto 1, a seguir.

\begin{tabular}{l|l|}
\hline Excerto 1 & Há quatro anos, tivemos no CEFET/RJ nossos \\
primeiros alunos cotistas. Para entrar lá, os jovens \\
fazem uma prova de seleção. Naquele ano, 50\% das \\
vagas foram destinadas para alunos negros, de \\
escolas públicas e com renda baixa. \\
\\
Lembro-me que levei um susto ao entrar em sala. \\
Havia negros e alunos extremamente diferentes na \\
forma de se expressar. Eu simplesmente não sabia \\
como lidar. Pensei em escrever uma carta para Dilma \\
reclamando. Se esse governo quer colocar cotistas \\
em sala, que ao menos nos dê uma certa infra- \\
estrutura para recebê-los! Psicólogos, pedagogos, \\
assistentes sociais... cadê esse time para nos ajudar? \\
Nada? Como assim?
\end{tabular}

Fonte: Print de texto postado no Facebook no dia 30/04/2016 às 14:27h

\section{Página 397, 2aㅡ coluna, 40 parágrafo}

Onde se lê: Em seguida, as designações "negros e alunos" apontam para um dado posicionamento que exclui os negros da posição de alunos.

Leia-se: Em seguida, as designações "negros e alunos", colocadas paralelamente, apontam para um dado posicionamento que exclui os negros da posição de alunos. O "negro" aqui serve como designação que nomeia o outro sobre o qual se vai falar ao longo do texto, configurando um elemento de alteridade marcado corporalmente que, por oposição, corrobora a construção de um ethos branco, superior, como veremos na sequência da análise.

\section{Página 397, 2aㅡ coluna, 50 parágrafo}

Onde se lê: A esse respeito, Mbembe (2014) pontua que a construção de sentidos sobre o substantivo negro, que embora tendo origens gregas, $[\ldots]$

Leia-se: $\quad$ Sobre o uso da designação negro, Mbembe (2014) pontua que a construção de sentidos sobre esse substantivo, que embora tenha origens gregas, $[\ldots]$ 


\section{Página 398, 1aㅡ coluna, 1o parágrafo}

Onde se lê: Designado por Mbembe como "razão negra"

Lea-se: Nomeado por Mbembe como "razão negra",

Onde se lê: Dialogando com Maingueneau (2008), podemos pensar em uma semântica global do racismo, com suas próprias restrições semânticas constituídas historicamente.

Leia-se: Dialogando com Maingueneau (2008), podemos pensar que o termo negro carrega em sua memória discursiva uma semântica global do racismo colonial, com suas próprias restrições constituídas historicamente.

\section{Página 398, 1ㅜㅡ coluna, 2o parágrafo}

Onde se lê: Voltando ao fragmento anterior do depoimento, o que causaria tamanho estranhamento "na forma de se expressar"? Quais seriam as formas de se expressar que não causariam estranhamento em uma cidade que se apresenta diversa e multicultural como o Rio de Janeiro, visto que a docente as classifica de "extremamente diferentes"?

Leia-se: Voltando ao fragmento anterior do depoimento (Excerto 1), dialogando com possíveis subentendidos, pode-se questionar: o que causaria tamanho estranhamento "na forma de se expressar"? Quais seriam essas formas de se expressar que não causariam estranhamento em uma cidade que se apresenta diversa e multicultural como o Rio de Janeiro, visto que a docente as classifica com a designação "extremamente diferentes"?

\section{Página 398, 1aㅡ coluna, 3ํㅜ parágrafo}

Onde se lê: Talvez, mas que devido à forma de se expressar, o estranhamento tenha sido causado pela ideia que cada um de nós tem [...]

Leia-se: Talvez, mas que devido à forma de se expressar, o estranhamento tenha sido causado pela ideia - um discurso naturalizado - que cada um de nós tem [...]

Onde se lê: [...] lugar simbólico de branquitude

Leia-se : [...] lugar simbólico de branquitude ${ }^{6}$

- Acrescentar nota de rodapé 6 :

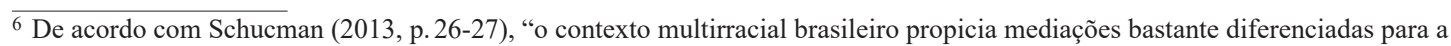
constituição de sujeitos e, portanto, para a subjetividade de brancos e não brancos. A marca dessa diferença e dessa desigualdade perpassa toda a socialização de tais indivíduos, na casa, na escola, na rua, e todos os espaços públicos são marcados pela supervalorização da branquitude e pela preferência do branco em relação ao não branco."

Onde se lê: E, no Brasil, onde o foco do racismo é a aparência externa e a identificação de traços mais ou menos europeus, o ser branco [...]

Leia-se: E, no Brasil, onde o foco do racismo é a aparência externa, e a identificação de traços mais ou menos europeus, o ser "branco" $[\ldots]$

- Acrescentar, logo após, o excerto 2:

Excerto 2

Percebi que muitos não sabiam o que era "estudar" porque, meodeos, nunca haviam estudado. Era como eu virar para qualquer outro na rua que nunca, por exemplo, estudou música e falar: você tem que treinar piano! Você tem que treinar piano! O cara ia sentar em frente ao piano e fazer o quê? Não saberia nem por onde começar! Quando percebi isso entrei em desespero porque o problema era muito maior do que pensava...

Fonte: Print de texto postado no Facebook no dia 30/04/2016 às 14:27h 


\section{Página 398, 1a coluna, 50 parágrafo}

Onde se lê: Mas em seguida "entra em desespero" ao constatar que há um problema muito maior: os cotistas não sabem estudar e nunca tinham estudado.

Leia-se: Mas em seguida, como consta no Excerto 2 afirma: "entrei em desespero" ao constatar que há um problema muito maior apontado no seguinte enunciado: "não sabiam o que era 'estudar' porque, meodeos, nunca haviam estudado".

\section{Página 398, 2aㅡ coluna, 1o parágrafo}

Onde se lê: E o enunciador vai construindo seu ethos, [...]

Leia-se: E o enunciador-professora vai construindo seu ethos, [...]

Onde se lê: [...] e com elas se importa e responde emocionalmente.

Leia-se: [...] e com elas se importa e responde emocionalmente. Entretanto, em seu relato ao desqualificar, por meio enunciados 'descritivos', esses alunos de modo tão explícito, não apenas tem como efeito ressaltar sua própria postura, mas também construir-se como racista (cf. MBEMBE, 2014; GUIMARÃES, 2009), ao reforçar uma desigualdade social, tornando-a discursivamente exótica e produzindo/inventando, assim como coloca Rocha (2014), uma dada qualidade de real.

$\rightarrow$ Em seguida, adicionar o excerto 3:

Excerto 3

O que fazer? Desistir? Deixar que todos repetissem?

Mas seriam muitos! O desespero une os seres

humanos que estão sob o mesmo inferno. Nós,

professores, fomos conversando e juntamente com

parte da equipe pedagógica, criando subsídios para

esses alunos.

Fonte: Print de texto postado no Facebook no dia 30/04/2016 às 14:27h

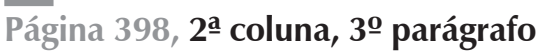

Onde se lê: O uso da primeira pessoa do plural no enunciado deixa evidente outra oposição: a daqueles que criaram o inferno - os cotistas, devido à dificuldade de não saberem estudar - e aqueles convocados para salvar a situação - professores e equipe pedagógica. Interessante, ainda, é notar que se a docente se alinha diversas vezes aos alunos não-cotistas, a outros professores, à equipe de pedagogos, psicólogos e assistentes sociais, em nenhum momento essa aliança ocorre entre ela e os alunos-cotistas.

Leia-se: $\quad$ No Excerto 3, destacamos a dêixis enunciativa, que pelo uso da primeira pessoa do plural no enunciado deixa evidente outra oposição subentendida: a daqueles que criaram o inferno - os cotistas, devido à dificuldade de não saberem estudar - e aqueles convocados para salvar a situação professores e parte da equipe pedagógica. Interessante, ainda, é notar que se a docente se alinha aos alunos não-cotistas, a outros professores, à equipe de pedagogos, psicólogos e assistentes sociais, em nenhum momento essa aliança, marcada pelo uso do dêitico nós ocorre entre ela e os alunos-cotistas.

\section{Página 398, 2a coluna, 4o parágrafo}

Onde se lê: [...] se pedagogos, psicólogos e assistentes sociais são demanda apenas dos alunos cotistas, há uma associação automática entre estes e questões que pressuponham profissionais de área tão específica da saúde? O atendimento psicológico em uma instituição como o Cefet/RJ sempre foi disponibilizado a servidores e discentes, antes da implementação do sistema de cotas.

Leia-se: [...] no momento em que pedagogos, psicólogos e assistentes sociais são demanda apenas para o atendimento aos alunos cotistas, não se está criando uma associação automática entre estes e questões que pressuponham profissionais de área tão específica da saúde? Principalmente considerando que o atendimento psicológico no Cefet/RJ já era disponibilizado a servidores e discentes, antes da implementação do sistema de cotas. 


\section{Página 398, 2aㅡ coluna, 50 parágrafo}

Onde se lê: Retomando o que já dissemos, o enunciador professora constrói um perfil do cotista, como o de um aluno que se "expressa de forma diferente", que "Não sabiam o que era estudar. Nunca tinham estudado" e que pressupunham a necessidade do trabalho de especialistas como pedagogos, psicólogos e assistentes sociais.

Leia-se: Retomando o que já dissemos, o enunciador-professora constrói um perfil do cotista, como o de um aluno que se "expressa de forma diferente" (Excerto 1), que "não sabiam o que era 'estudar' porque, meodeos, nunca haviam estudado" (Excerto 2) e que pressupunham a necessidade do trabalho de especialistas como pedagogos, e psicólogos e assistentes sociais (Excerto 3). Todos enunciados descritivos que constroem esse outro, cotista, como inferior em uma hierarquia social.

\section{Página 398, 2- coluna, 60 parágrafo}

Onde se lê: "mal sabia pegar no lápis por falta de hábito".

Leia-se: "mal sabia pegar no lápis por falta de hábito..." (Excerto 4).

- Após o 60 parágrafo, adicionar o excerto 4:

\begin{tabular}{l|l|} 
Excerto 4 & $\begin{array}{l}\text { A ficha caiu quando um menino de boné e cordão } \\
\text { prata veio até mim e falou: "Professora, você fala que } \\
\text { eu tenho que estudar. O que seria exatamente isso? } \\
\text { Eu não quero perder essa oportunidade. Me ajuda..." } \\
\text { Esse menino mal sabia pegar no lápis por falta de } \\
\text { hábito... }\end{array}$
\end{tabular}

Fonte: Print de texto postado no Facebook no dia 30/04/2016 às 14:27h

\section{Página 399, 1aㅡ coluna, 1o parágrafo}

Onde se lê: "um menino de boné e cordão prata".

Leia-se: "um menino de boné e cordão prata" (Excerto 4).

\section{Página 399, 1aㅡ coluna, 2o parágrafo}

Onde se lê: "Eu não quero perder essa oportunidade. Me ajuda..."

Leia-se: "Eu não quero perder essa oportunidade. Me ajuda..." (Excerto 4).

\section{Página 399, 1a coluna, 3o parágrafo}

\section{Onde se lê: CEFET}

\section{Leia-se: Cefet/RJ}

Onde se lê: [...] cidade do Rio de Janeiro e, por esse motivo, [...]

Leia-se: [...] cidade do Rio de Janeiro, e, por esse motivo, [...]

จ Após o 3 o parágrafo, adicionar excerto 5 :

Excerto 5

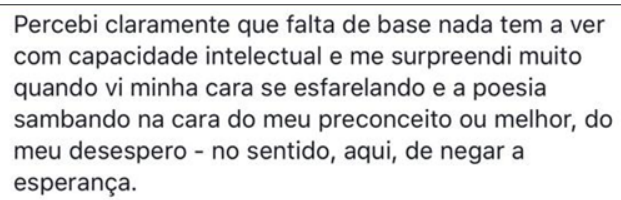

Fonte: Print de texto postado no Facebook no dia 30/04/2016 às 14:27h

\section{Página 399, 1a coluna, 5o parágrafo}

Onde se lê: O enunciado marca um processo de transição, a partir de uma percepção que rompe com um posicionamento anterior, o de que a falta de base teria uma correlação com a capacidade intelectual - um discurso recorrente, no racismo científico do início século $\mathrm{XX}$-, e da percepção do 
próprio preconceito, que é atenuado ao ser reformulado no texto, como desespero. Do ponto de vista de um discurso antirracista, tal mudança de percepção seria fundamental, mas não chega a se efetivar discursivamente no texto, uma vez que é desmontada por enunciados racistas ao longo do mesmo.

Leia-se: $\quad$ O enunciado marca um processo de transição, por meio de uma descrição que funciona analogamente à uma negação polêmica (DUCROT, 1987), tensionando dois discursos, a partir de uma percepção do sujeito: "percebi claramente" (Excerto 5) que rompe com um posicionamento anterior, o de que a falta de base teria uma correlação com a capacidade intelectual - um discurso recorrente no racismo científico do início século XX (GUIMARÃES, 2009) -, e da percepção do próprio preconceito, que é atenuado ao ser reformulado no texto, como desespero. Do ponto de vista de um discurso de fato antirracista, tal mudança de percepção seria fundamental, mas não chega a se efetivar discursivamente no texto, uma vez que é desmontada por enunciados racistas ao longo do mesmo. Passemos ao Excerto 6:

$\rightarrow$ Adicionar após o 6 o parágrafo o excerto 6 :

Excerto 6

Tivemos que lidar também com tensões e preconceitos que existiam entre eles. Por exemplo, alguns alunos que vieram de escolas particulares com família bem estruturada não entendiam por quê o colega não fazia o trabalho direito. Inicialmente, houve, em algumas turmas, segregação. No jogo de xadrez, por exemplo, onde temos peças pretas e brancas, eles perguntavam quem seria os cotistas e os não-cotistas...

Fonte: Print de texto postado no Facebook no dia 30/04/2016 às $14: 27 \mathrm{~h}$

\section{Página 399, 1a coluna, 7o parágrafo}

Onde se lê: E esses dois fatores garantiriam o saber fazer- o-trabalho-direito?

Leia-se: E esses dois fatores garantiriam o saber-fazer-o-trabalho-direito?

Passemos ao Excerto 7, com mais uma sequência do relato:

จ Após o 70 parágrafo, adicionar o excerto 7 :

Excerto 7

Este ano (como em outros nas minhas turmas do primeiro ano), minha primeira avaliação foi coletiva e não individual. Os alunos tinham que fazer um grupo, estudar entre eles e, no dia da prova, eu faria uma pergunta em que somente um deles, sorteado por mim na hora, resolveria no quadro a questão por mim colocada. A nota do aluno escolhido seria a nota de todos os demais componentes daquele grupo. Essa foi uma forma que encontrei de forçar os alunos privilegiados a me ajudarem a ajudar os menos privilegiados.

Fonte: Print de texto postado no Facebook no dia 30/04/2016 às $14: 27 \mathrm{~h}$

\section{Página 399, 2aㅡ coluna, 2o parágrafo}

Onde se lê: [...] é o uso do verbo ajudar [...]

Leia-se: [...] é o uso do verbo ajudar [...]

Onde se lê: O aluno-precisa ser assistido, ajudado, [...]

Leia-se: $\quad$ O aluno-cotista precisa ser assistido, ajudado, [...]

Onde se lê: "Afinal esse ser já tinha sofrido na pele o diabo da exclusão social e se sentia amedrontado perante os demais"

Leia-se: “esse ser já tinha sofrido na pele o diabo da exclusão social e se sentia amedrontado perante os demais" (excerto 8).

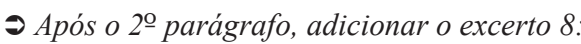




\begin{tabular}{|l|l|}
\hline Excerto 8 & um chamado comum porque esse ser já tinha sofrido \\
na pele o diabo da exclusão social e se sentia \\
amedrontado perante os demais. "Você vai ser o \\
diferencial na vida dele. Dependendo da forma em \\
que se chegue a ele, você pode despertar um artista, \\
um sábio, um colega pensante ou minar qualquer \\
coisa boa que possa emergir." A menina de 15 anos \\
me olhou assustada. Nunca talvez ninguém havia Ihe \\
dado tanta responsabilidade. Continuei: "Sim. Temos \\
que, acima de tudo, cuidar uns dos outros sempre. \\
Isso se aprende também na escola."
\end{tabular}

Fonte: Print de texto postado no Facebook no dia 30/04/2016 às $14: 27 \mathrm{~h}$

\section{Página 399, 2a coluna, 3o parágrafo}

Onde se lê: "[...] qualquer coisa boa que possa emergir"

Leia-se: “[...] qualquer coisa boa que possa emergir.” (Excerto 8)

Onde se lê: O referido pensamento é reforçado pelos fragmentos.

Leia-se: $\quad$ O referido pensamento é reforçado pelo enunciado no Excerto 9.

- Acrescentar após o 3 o parágrafo o excerto 9:

Excerto 9

Ao final da aula, a aluna veio emocionada falar

comigo: "Professora, fiz o que a senhora falou.

Chamei o menino de outra forma e com jeitinho fui

tirando dele o que ele sabia e mostrando a ele como

agir. Estudamos a tarde toda. Você viu como ele falou

bem?". Havia o orgulho e a felicidade em ter ajudado o

próximo e incluir um que, em outra época, seria

completamente jogado às margens da nossa

sociedade sendo o que chamamos de "marginal" em

sua essência.

Fonte: Print de texto postado no Facebook no dia 30/04/2016 às 14:27h

\section{Página 399, 2a coluna, 60 parágrafo}

Onde se lê: No que se refere ao ethos mobilizado, o enunciador professora constrói-se como pessoa branca, de família estruturada e que sempre soube como estudar.

Leia-se: $\quad$ No que se refere ao ethos mobilizado pelo recurso a enunciados descritivos, designações, dêixis enunciativa e subentendidos, o enunciador-professora constrói-se discursivamente como pessoa branca, de família estruturada e que sempre soube como estudar.

\section{Página 400, 1a coluna, 1o parágrafo}

Onde se le: O coenunciador construído no texto parece pertencer ao mesmo mundo do enunciador e dos "alunos privilegiados", o que anteriormente chamamos de seguidores.

Leia-se: O coenunciador construído no texto, que em função do gênero discursivo mobilizado, chamamos anteriormente de seguidores, parece pertencer ao mesmo mundo do enunciador e dos "alunos privilegiados".

\section{Página 400, 1a coluna, 2 o parágrafo}

Onde se lê: dependente de uma intervenção externa

Leia-se: dependente de uma intervenção do outro จ Após o $2^{\mathrm{O}}$ parágrafo, adicionar o $3^{\mathrm{O}}$ parágrafo:

Em síntese, a identificação da construção de um ethos racista no texto em análise dá-se principalmente por meio do processo de alteridade, isto é, pelo que o enunciador-professora diz sobre seus alunos cotistas. É preciso ainda explicitar que tal ethos não se caracteriza para todos os interlocutores do mesmo modo, uma vez que o racismo, no contexto brasileiro, não costuma ser assumido enquanto tal e o estereótipo tipicamente associado ao racista seria um sujeito muito mais agressivo. No entanto, 
ao inferiorizar discursivamente os sujeitos alunos cotistas, identificados por uma corporalidade negra, um certo modo de vestir-se que os aproxima de um estereótipo ligado às culturas periféricas (boné e cordão de prata) e uma personalidade representada por uma limitação (não sabia o que era "estudar"), o enunciador constrói-se como superior e é por essa posição de superioridade, que se pode compreendê-lo como racista. Outro aspecto constitutivo da cena enunciativa que sustenta e é sustentada por tal ethos, é a construção de um fiador salvador, que ao identificar as 'limitações' do aluno cotista, coloca-se como benfeitor, apagando qualquer possibilidade de agência desse sujeito. Essa figura salvadora ainda agrega em si uma identidade de guia moral que ensina os alunos não cotistas, essencialmente privilegiados, a praticarem a 'compaixão' com o outro inferior.

\section{Página 400, 1a coluna, 1ํ parágrafo (Considerações finais)}

Onde se lê: Nos propusemos,

Leia-se: Propusemo-nos,

\section{Página 400, 1a coluna, 2o parágrafo (Considerações finais)}

Onde se lê: Reforça essa necessidade de redenção, [...]

จ Dar entrada de parágrafo

\section{Página 400, 2- coluna (Referências)}

Onde se lê: BAKHTIN, Mikhail. Estética da criação verbal. São Paulo: Martins Fontes, 2000.

DUCROT, Oswald. O dizer e o dito. Campinas: Pontes, 1987.

FANON, Frantz. Pele negra máscaras brancas. Bahia: Editora Edufba, 2008.

FOUCAULT, Michel. A ordem do discurso. 19. ed. São Paulo: Edições Loyola, 2009.

FOUCAULT, Michel. A arqueologia do saber. Rio de Janeiro: Forense Universitária, 2008.

FOUCAULT, Michel. Em defesa da sociedade: curso no Collège de France (1975-1976). São Paulo: Martins Fontes, 2002.

GUIMARÃES, Antonio Sérgio A.; RIOS, Flavia M. Cotas nas universidades públicas. Afro-Ásia, Salvador, n. 50, p. 251-256, dez. 2014. Disponível em: <http://www.scielo.br/scielo.php?script=sci_arttext\&pid=S0002-05912014000 200251\&lng=en\&nrm=iso >. Acesso em: 15 maio 2018. http://dx.doi.org/10.1590/0002-05912014v50ant251

GUIMARÃES, Antonio Sérgio Alfredo. Depois da democracia racial. Tempo soc., São Paulo, v. 18, n. 2, p. 269-287, nov. 2006. Disponível em: <http://www.scielo.br/scielo.php?script=sci_arttext\&pid=S0103-20702006000200014\&ln $\mathrm{g}=\mathrm{en} \& \mathrm{nrm}=\mathrm{iso}>$. Acesso em: 15 maio 2018. http://dx.doi.org/10.1590/S0103-20702006000200014

HALL, Stuart. Raça, o significante flutuante. Z Cultural, Revista do Programa Avançado de Cultura Contemporânea, ano VIII, n. 2, 2015.

HALL, Stuart. A identidade cultural na pós-modernidade. Rio de Janeiro: Lamparina, 2014.

HALL, Stuart. Quem precisa da identidade? In: SILVA, Tomaz Tadeu da (Org.). Identidade e diferença. A perspectiva dos Estudos Culturais. Petrópolis: Vozes, 2009. p. 103-133.

HALL, Stuart. Da Diáspora. Identidades e Mediações Culturais. Organização Liv Sovik. Belo Horizonte: Editora da UFMG, 2003.

KOMESU, Fabiana. Entre o público e o privado: um jogo enunciativo na constituição do escrevente de blogs da Internet. 271 p. Tese (Doutorado em Linguística) - Instituto de Estudos da Linguagem, Universidade Estadual de Campinas, Campinas, 2005.

MAINGUENEAU, Dominique. Análise de textos de comunicação. 6. ed. ampl. São Paulo: Cortez, 2013.

MAINGUENEAU, Dominique. Gênese dos discursos. São Paulo: Parábola Editorial, 2008.

MAINGUENEAU, Dominique. Cenas da enunciação. Curitiba: Criar Edições, 2006.

MAINGUENEAU, Dominique. Ethos, cenografia, incorporação. In: AMOSSY, R. (Org.). Imagens de Si no Discurso: a construção do ethos. São Paulo: Contexto, 2005.

MAINGUENEAU, Dominique. Novas tendências em análise do discurso. 3. ed. Campinas, São Paulo: Pontes; Editora da UNICAMP, 1997.

MBEMBE, Achile. Crítica da Razão Negra. Lisboa: Antígona, 2014.

MOITA LOPES, Luiz Paulo da. Linguística Aplicada como lugar de construir verdades contingentes: sexualidades, ética e política. Gragoatá, n. 27, p. 33-50, 20 sem. 2009. Disponível em: <http://www.uff.br/revistagragoata/revistas/ gragoata27web.pdf>. Acesso em: 25 mar. 2018. 
MOITA LOPES, Luiz Paulo da (Org.). Por uma linguística aplicada indisciplinar. São Paulo: Parábola Editorial, 2006.

MUNANGA, Kabengele. Políticas de ação afirmativa em benefício da população negra no Brasil: um ponto de vista em defesa de cotas. Sociedade e Cultura, v. 4, p. 31-43, jul.-dez. 2001. Disponível em: <http://www.redalyc.org/articulo. oa? id=70311216002>. Acesso em: 25 mar. 2018.

PASSOS, Ana Helena Itamar; MIRANDA, Cláudia. Estudos críticos da branquitude e educação afrocentrada: novos aportes para uma educação antirracista. Anais do XI Congresso Luso Afro brasileiro de Ciências Sociais. Salvador, UFBA, 2011.

PIOVESAN, Flávia. Ações afirmativas no brasil: desafios e perspectivas. Estudos Feministas, v. 16, n. 3, p. 887-896, set.-dez. 2008.

SANTOS, Adilson Pereira dos. Itinerário das ações afirmativas no ensino superior público brasileiro: dos ecos de Durban à Lei das Cotas. Revista de C. Humanas, Viçosa, v. 12, n. 2, p. 289-317, jul.-dez. 2012.

ROCHA, Décio. Representação e intervenção: produção de subjetividade na linguagem. Gragoatá (UFF), v. 21, p. 355- 372, 2006.

SOVIK, Liv. Aqui ninguém é branco: hegemonia branca e media no Brasil. In: WARE, Vron (Org.). Branquidade: identidade branca e multiculturalismo. Rio de janeiro: Garamond, 2004, p. 363-386.

Leia-se: $\quad$ BAKHTIN, Mikhail. Estética da criação verbal. São Paulo: Martins Fontes, 2000.

DAMATTA, Roberto. Notas sobre o racismo à brasileira. In: SOUZA, Jessé (org.). Multiculturalismo e racismo: uma comparação Brasil-Estados Unidos. Brasília: Paralelo 15, 1997. p. 69-76.

DUCROT, Oswald. O dizer e o dito. Campinas: Pontes, 1987.

FANON, Frantz. Pele negra máscaras brancas. Bahia: Editora Edufba, 2008.

FOUCAULT, Michel. A arqueologia do saber. Rio de Janeiro: Forense Universitária, 2008.

FOUCAULT, Michel. Em defesa da sociedade: curso no Collège de France (1975-1976). São Paulo: Martins Fontes, 2002.

FOUCAULT, Michel. A ordem do discurso. 19. ed. São Paulo: Edições Loyola, 2009.

GUIMARÃES, Antonio Sérgio Alfredo.; RIOS, Flavia M. Cotas nas universidades públicas. Afro-Ásia, Salvador, n. 50, p. 251-256, dez. 2014. Disponível em: http://www.scielo.br/scielo.php?script=sci arttext\&pid= S0002-05912014000200251\&lng=en\&nrm=iso. Acesso em: 15 maio 2018. http://dx.doi.org/10.1590/000205912014v50ant251

GUIMARÃES, Antonio Sérgio Alfredo. Depois da democracia racial. Tempo soc., São Paulo, v. 18, n. 2, p. 269-287, nov. 2006. Disponível em: http://www.scielo.br/scielo.php?script=sci_arttext\&pid=S0103-20702006000200014\& lng=en\&nrm=iso. Acesso em: 15 maio 2018. http://dx.doi.org/10.1590/S0103-20702006000200014

GUIMARÃES, Antonio Sérgio Alfredo. Racismo e antirracismo no Brasil. São Paulo: Editora 34, 2009.

HALL, Stuart. A identidade cultural na pós-modernidade. Rio de Janeiro: Lamparina, 2014.

HALL, Stuart. Da Diáspora. Identidades e Mediações Culturais. Organização Liv Sovik. Belo Horizonte. Editora da UFMG, 2003.

HALL, Stuart. Quem precisa da identidade? In: SILVA, Tomaz Tadeu da (org.). Identidade e diferença. A perspectiva dos Estudos Culturais. Petrópolis, RJ: Vozes, 2009. p. 103-133.

HALL, Stuart. Raça, o significante flutuante. Z Cultural, Revista do Programa Avançado de Cultura Contemporânea, ano VIII, n. 2, 2015.

KOMESU, Fabiana. Entre o público e o privado: um jogo enunciativo na constituição do escrevente de blogs da Internet. 2005. 271 p. Tese (Doutorado em Linguística) - Instituto de de Estudos da Linguagem, Universidade Estadual de Campinas, Campinas.

MAINGUENEAU, Dominique. Análise de textos de comunicação. 6. ed. ampl. São Paulo: Cortez, 2013. 
MAINGUENEAU, Dominique. Cenas da enunciação. Curitiba, PR: Criar Edições, 2006.

MAINGUENEAU, Dominique. Gênese dos discursos. São Paulo: Parábola Editorial, 2008.

MAINGUENEAU, Dominique. Novas tendências em análise do discurso. 3. ed. Campinas, SP: Pontes: Editora da UNICAMP, 1997.

MAINGUENEAU, Dominique. Ethos, cenografia, incorporação. In: AMOSSY, R. (org.). Imagens de si no discurso. A construção do ethos. São Paulo: Contexto, 2005.

MBEMBE, Achile. Crítica da razão negra. Lisboa: Antígona, 2014.

MOITA LOPES, Luiz Paulo da (org.). Por uma linguística aplicada indisciplinar. São Paulo: Parábola Editorial, 2006.

MOITA LOPES, Luiz Paulo da. Linguística Aplicada como lugar de construir verdades contingentes: sexualidades, ética e política. Gragoatá, n. 27, p. 33-50, 2 sem. 2009. Disponível em: http:/www.uff.br/revistagragoata/revistas/ gragoata27web.pdf. Acesso em: 25 mar. 2018.

MUNANGA, Kabengele. Políticas de ação afirmativa em benefício da população negra no Brasil: um ponto de vista em defesa de cotas. Sociedade e Cultura, v. 4, p. 31-43, jul.-dez. 2001. Disponível em: http://www.redalyc.org/ articulo.oa? id=70311216002. Acesso em: 25 mar. 2018.

PASSOS, Ana Helena Itamar; MIRANDA, Cláudia. Estudos críticos da branquitude e educação afrocentrada: novos aportes para uma educação antirracista. Anais do XI Congresso Luso Afro-brasileiro de Ciências Sociais. Salvador, UFBA, 2011

PIOVESAN, Flávia. Ações afirmativas no brasil: desafios e perspectivas. Estudos Feministas, v. 16, n. 3, p. 887-896, set.-dez. 2008.

ROCHA, Décio. Representação e intervenção: produção de subjetividade na linguagem. Gragoatá (UFF), v. 21, p. 355-372, 2006.

SANTOS, Adilson Pereira dos. Itinerário das ações afirmativas no ensino superior público brasileiro: dos ecos de Durban à Lei das Cotas. Revista de C. Humanas, Viçosa, v. 12, n. 2, p. 289-317, jul./dez. 2012.

SCHUCMAN, Lia. Vainer. Entre o encardido, o branco e o branquíssimo: branquitude, hierarquia e poder na cidade de São Paulo. São Paulo: Annablume, 2013.

SOVIK, Liv. Aqui ninguém é branco: hegemonia branca e media no Brasil. In: WARE, Vron (org.). Branquidade: identidade branca e multiculturalismo. Rio de Janeiro: Garamond, 2004. p. 363-386.

A Equipe Editorial pede desculpas aos envolvidos pelo transtorno.

Publicado em: 21/06/2019. 